\title{
Research Note: Effect of Grapevine Canopy Side on Selected Sensory Attributes of Pinotage and Cabernet Sauvignon Wines
}

\author{
P.P. Minnaar ${ }^{*}$, N.P. Jolly ${ }^{1}$, N.S. Ntushelo ${ }^{2}$ \\ (1) ARC Infruitec-Nietvoorbij, Private Bag X5026, Stellenbosch 7600, South Africa \\ (2) ARC Biometry, Private Bag X5026, Stellenbosch 7600, South Africa
}

Submitted for publication: July 2019

Accepted for publication: February 2020

Key words: Red wine, viticultural practices, canopy side, astringency, colour intensity, mouthfeel

Grapevine row direction, canopy exposure and grape maturity can define the sensory attributes of wine. From this perspective, canopy exposure that favours colour intensity, astringency, aroma intensity and balanced acidity could result in improved wine quality. The aim of this study was to examine the effect of canopy exposure on selected sensory attributes of Pinotage and Cabernet Sauvignon wines from Paarl, Durbanville and Darling in South Africa. Pinotage and Cabernet Sauvignon grapes were harvested from both sides of the canopy of vines planted to E-W and N-S directions. Wines were made from the harvested grapes. Grapes and wines underwent physicochemical and sensory analysis. Durbanville Cabernet Sauvignon from the south side had decreased alcohol content. Total acidity, residual sugar (RS) and pH were not different between sides. Wines from the east side had increased colour, aroma, mouthfeel and overall quality. Paarl Cabernet Sauvignon was not different between sides for any physicochemical characteristics, except TA. Wines from the south side had increased colour, aroma, mouthfeel and overall quality. Darling Pinotage was not different between sides for any physicochemical characteristics. Wines from the west side had increased intensity of aroma and acidity, whereas Durbanville Pinotage from the east side had increased alcohol, pH, TA, colour and aroma intensity, as well as overall quality. The results confirm that canopy exposure has an effect on the wine sensory attributes. This investigation illustrates the variation in sensory attribute scores of Pinotage and Cabernet Sauvignon wines from different canopy sides. Canopy exposure in a vineyard of a specific region, orientated to an $\mathrm{E}-\mathrm{W}$ or $\mathrm{N}-\mathrm{S}$ direction, which favours colour intensity, aroma intensity and/or mouthfeel, could result in improved wine quality. Future investigations should focus on samples collected over at least three consecutive vintages, as well as the monitoring of temperature and photosynthetic active radiation.

\section{INTRODUCTION}

Grapes comprise of numerous primary metabolites (white, red and teinturier cultivars), such as sugars, organic acids, amino acids as well as secondary metabolites, i.e. flavonoids and non-flavonoids (Gawel, 1998). The latter include anthocyanins, flavan-3-ols, flavonols, flavononols and phenolic acids, which are present in the grape berry (Downey et al., 2006).

Phenolic concentrations of grapes are determined by genetics (Downey et al., 2006), but can be affected by vineyard practices, microclimate (e.g. row direction, diurnal temperature, trellis system, precipitation, light interception, canopy exposure), degree of berry ripeness and vinification processes (Gawel \& Godden 2008; Hunter \& Volschenk 2008; Río-Segade et al., 2009; Chorti et al., 2010; Rustioni et al., 2011; Friedel et al., 2012; Minnaar et al., 2013; Allegro et al., 2019).

Canopy exposure altered the interception of light by
Tannat grapes and hence affects the accumulation of phenols throughout grape ripening (González-Neves et al., 2004; Pérez-Lamela et al., 2007).

Hunter and Volschenk (2008) demonstrated that Syrah grapes harvested from east-west (E-W) and northwestsoutheast (NW-SE) row directions showed differences in grape skin colour. An increase in grape skin tannin concentrations was reported in Nebbiolo (Chorti et al., 2010), Pinot Noir (Rustioni et al., 2011) and Riesling (Friedel et al., 2012) grapes exposed to direct sunlight (low-vigour vines) compared to grapes from dense canopies. Moderate exposure of grape bunches to light favours colour accumulation (Chorti et al., 2010). Minnaar et al. (2013) showed that grape skin colour was higher in Syrah grapes harvested from a NW-SE and northeast southwest (NE-SW) row direction, compared to an E-W and north-south $(\mathrm{N}-\mathrm{S})$ row direction.

Phenolics can define the quality and character of wine

*Corresponding author: E-mail address: minnaarp@arc.agric.za

Acknowledgements: The authors thank the Agricultural Research Council, for financial support, and Messrs Christopher Paulse and Goliat Pikkeur, for their assistance in grape collection 
(Downey et al., 2006). The colour intensity and astringency of wine are determined by the levels of anthocyanins and flavan-3-ols (tannins) in grapes when phenolic compounds are released from the grapes during the vinification process (Mané et al., 2007). Viticultural practices such as canopy management, trellis systems and canopy exposure affect the anthocyanin (wine colour) and flavan-3-ols (mouthfeel) content of Pinot noir wines (Cortell et al., 2007). Enhancement of light penetration into the fruit zone by canopy management has resulted in increased anthocyanins in Grenache wines (Louarn et al., 2008).

Hunter and Volschenk (2018) found that Shiraz wines from grapes (South Africa) from the east side of the canopy (N-S direction) had more intense colour than grapes from the west side of the canopy. They also reported that wines of grapes from the north side (E-W direction) of the canopy had more red colour than wines of grapes from the south side.

Allegro et al. (2019) reported more intense colour in Vitis vinifera L. cv Grechetto Gentile wines from overexposed grapes (Italy) compared to shaded grapes (dense canopies, control), whereas the aroma was more intense in the control wines.

The colour intensity and mouthfeel (astringency) of wine are amongst the important determinants of wine quality, and of consumer preference and acceptance (Guinard et al., 1996). The in-mouth sensory properties of red wine involve various interacting sensations of acidity, flavour and astringency (Gawel, 1997). The oral sensation referred to as astringency is a primary mouthfeel attribute in red wine and is considered an important aspect in describing the sensory properties. It is widely acknowledged that high-quality red wines have balanced levels of astringency and acid intensity (Noble, 1995).

Ryona et al. (2008) reported that E-W-exposed Cabernet Franc grapes from Spain (low light exposure all day in fruiting zone) had a lower aroma concentration than shaded grapes (dense canopy, interior) from the same row directions. Aroma compounds can also contribute to wine quality (Vilanova \& Martinez, 2007). Increased concentrations of aroma compounds, particularly in Syrah wines, are associated with increased sunlight penetration and light quality in the fruit zone (Bureau et al., 2000). Ultraviolet $B$ radiation affected the accumulation of terpenes in wines from Cabernet Sauvignon grapes (Gil et al., 2013), but no effect on methoxypyrazine concentrations was evident (Gregan et al., 2012).

In South Africa, there are different terroirs in the grapegrowing region of the Western Cape. Pinotage and Cabernet Sauvignon grapes are planted extensively in several grapegrowing regions of the country, hence the aim of this investigation was to evaluate the effect of canopy side on selected sensory attributes of Pinotage and Cabernet Sauvignon wines originating from three different grapegrowing regions in the Western Cape province of South Africa.

\section{MATERIALS AND METHODS}

\section{Experimental sites}

A completely randomised design was used and each vineyard block was an experimental unit with twelve uniform rows.
The vineyard blocks were situated in Paarl (-33.4299 Lat.; 19.2180 Long.), Darling (-33.4117 Lat.; 18.45046 Long.) and Durbanville (-33.8333 Lat.; 18.6333 Long.), representing two grape cultivars, viz. Cabernet Sauvignon and Pinotage planted to E-W and N-S row directions (Table 1).

Vineyard row directions were N-S and E-W, row spacing was $2.5 \mathrm{~m}$ and vine spacing was $1.8 \mathrm{~m}$. Cabernet Sauvignon vineyards were between 8 and 11 years old and Pinotage vineyards between 10 and 12 years old. All vines received drip irrigation during January, February, and March as supplementary irrigation. Temperature data was obtained from weather stations closest to the experimental site. The locations of the weather stations were Paarl ( -33.7135 Lat. and 19.01295 Long.), Darling (-33.4117 Lat. and 18.45046 Long.) and Durbanville (-33.8333 Lat. and 18.6333 Long.)

\section{Grape harvesting}

Grapes represented a spread over twelve rows per vineyard block, consisting of eighty individual grapevines per row, from which the most upfront exposed bunches were collected from the respective canopy sides, i.e. east, west, north and south. Grape bunches of the north and south sides of the canopies were moderately exposed to light the entire day, while east- and west-facing canopies received high light exposure in the morning and afternoon in the fruit zone (Hunter et al., 2010). One crate per row per canopy side was collected. Grapes were harvested manually, placed in crates, and transported to the cellar on the same day.

Grape ripeness levels were determined by a handheld refractometer prior to harvest. Grape ripeness levels at the time of harvest varied from $21.1^{\circ}$ Brix (lowest level) to $25.5^{\circ} \mathrm{Brix}$ (highest level) among the grape cultivars (Table 1). Grapes were harvested during the months of February and March of the specific year. Grape cultivar, grape-growing region, date of harvest, rootstock, row direction, canopy side, number of samples collected and grape ripeness levels are listed in Table 1. Daytime minimum and maximum temperatures per region per month, as well as total precipitation, are listed in Table 2.

\section{Small-scale winemaking}

Wines were made from the harvested grapes, i.e. twelve crates per vineyard block, representing a canopy side and twelve replicate treatments (Table 1). Wines were made according to a standard small-scale winemaking procedure at the ARC Infruitec-Nietvoorbij research cellar. Grape bunches were mechanically de-stemmed and crushed. The must was inoculated with $30 \mathrm{~g} / \mathrm{hl}$ Saccharomyces cerevisiae strain VIN 13 yeast (Anchor Oenology, South Africa). Grape must was fermented in temperature-controlled rooms ( $c a$. $25^{\circ} \mathrm{C}$ ) on the skins in open fermenters, with three punch downs per day for approximately four days until the sugar levels dropped to approximately $5^{\circ}$ Brix. Thereafter, wines were pressed using a small balloon press ( $c$. $200 \mathrm{KPa}$ ) and transferred to stainless steel canisters $(20 \mathrm{~L})$ equipped with fermentation locks. The wines were allowed to ferment further for approximately one week until glucose levels were below $2 \mathrm{~g} / \mathrm{L}$ as determined by a Clinitest ${ }^{\circledR}$ method (Bayer, South Africa). Malolactic fermentation was not induced for any of the wines. Wines were cold stabilised for two weeks, 

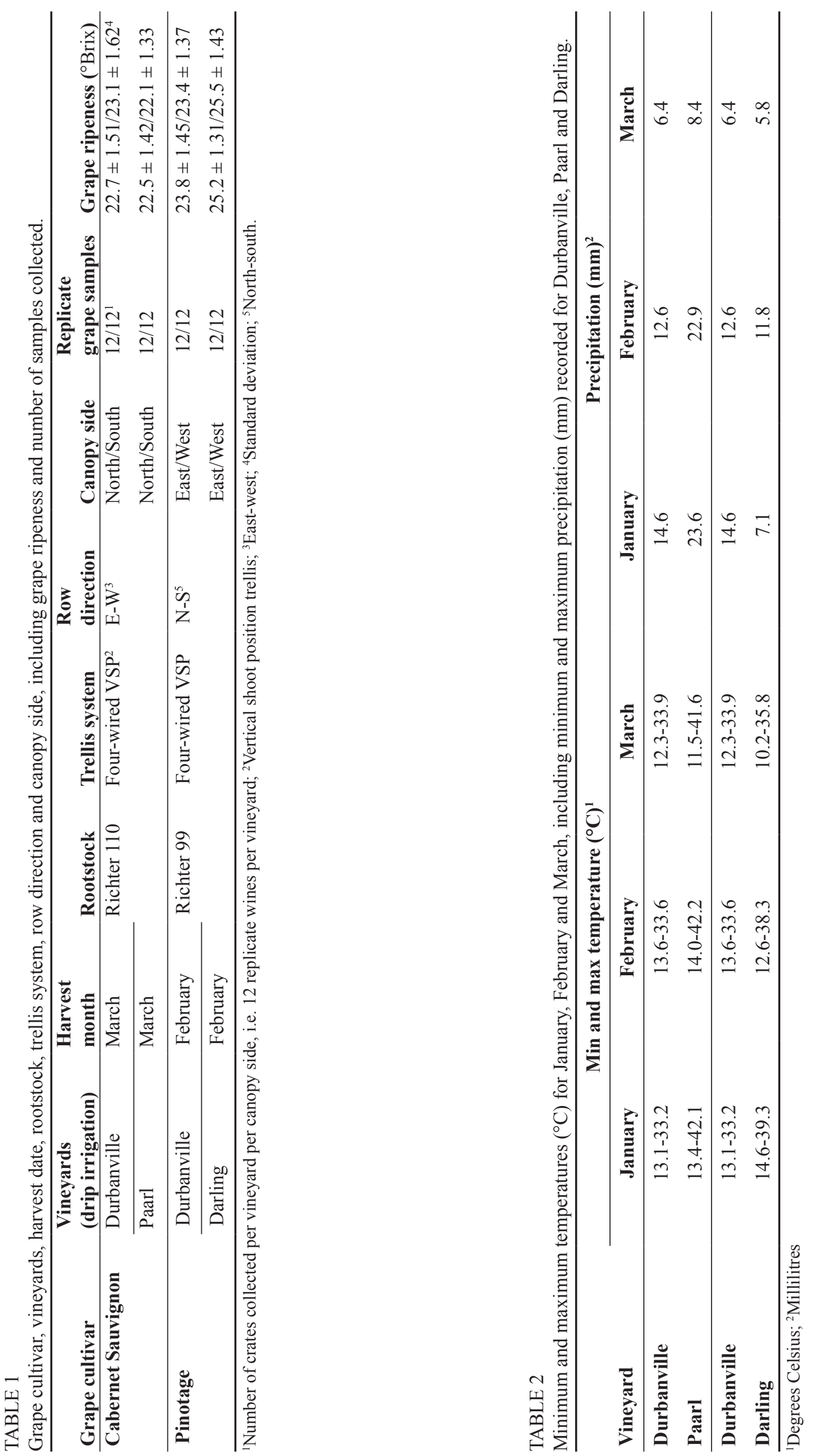
filtered and bottled under nitrogen at room temperature.

\section{Physicochemical characteristics}

Grape must was analysed for total soluble solids prior to inoculation (Foss ${ }^{\circledR}$ Winescan). Standard chemical analyses of wine were done, viz. pH, total acidity (TA), ethanol and residual sugar levels were determined by means of Foss ${ }^{\circledR}$ Winescan (IWBT, Stellenbosch University) one month after bottling.

\section{Sensory analysis}

Sensory analyses were conducted four months after bottling on 96 wines, i.e. 48 each for Cabernet Sauvignon and Pinotage. A panel of 13 expert wine tasters (three women and 11 men, aged between 22 and 50 years), comprising mainly Agricultural Research Council staff members but also invited commercial winemakers, participated in the sensory analysis. Panel members had between two and 20 years' experience in wine evaluation. Wines were evaluated in one session (one day) in a temperature-controlled room at $\pm 20^{\circ} \mathrm{C}$ with fluorescent light. Water and wheat biscuits (neutral taste) were provided to tasters for palate cleansing between samples.

Sensory analysis involved the evaluation of colour intensity, aroma intensity, acid intensity, astringency, mouthfeel, and overall quality. Tasting took place in separate tasting booths. Each taster received ca. $30 \mathrm{~mL}$ of each wine sample in an ISO international wine-tasting glass. Twentyfour wine samples, representing both treatments (canopy side) of each grape cultivar, were presented to the tasters in a random order per tasting session. The tasters rated the wine attributes on a $10 \mathrm{~cm}$ unstructured line scale from low to high intensity (colour, aroma, acidity), thin to full bodied (astringency, mouthfeel), and unacceptable to excellent (overall quality).

\section{Statistical analysis}

Univariate analysis of variance was performed on all variables using the general linear models procedure of the SAS statistical software, version 9.2 (SAS Institute Inc., 1999). To confirm panel reliability, sensory data was pre-processed employing the model suggested by Næs et al. (2010) that includes panellist, replicate, treatment and interaction effects, with only treatment as fixed effect and all other effects random. The Shapiro-Wilk test was performed on the standardised residuals from the model to test all variables for deviation from normality (Shapiro \& Wilk, 1965). Outliers were removed when the standardised residual for an observation deviated by more than three standard deviations from the model value. Following the confirmation of panel reliability and normality, univariate analysis of variance was performed according to the experimental design, using the means over tasters. Fisher's $t$ least-significant difference was calculated at a 5\% level of significance to compare treatment means (Ott, 1998). A probability level of 5\% was considered significant for all tests. Sensory attributes and physicochemical characteristics variables were subjected to analysis of variance.

\section{RESULTS AND DISCUSSION Cabernet Sauvignon}

The results are reported in Table 3. Grapevines growing in $\mathrm{E}-\mathrm{W}$ directions receive low light exposure all day in the fruit zone (Hunter et al., 2010). Alcohol, TA, pH and acid intensity were not significantly different between sides for the Durbanville wines (cool climate). However, wines from the north side scored significantly higher in colour, aroma, mouthfeel and astringency than wines from the south side. The tasters preferred wines from the north side. Gawel et al. (2013) reported that a low $\mathrm{pH}$ could contribute to mouthfeel differences. The reduced aroma in wines from the south side may be due to the decrease in methoxypyrazines (Ryona et al., 2008). Hunter and Volschenk (2008) reported that Shiraz grapes from E-W and NW-SE row directions were notably different in berry skin colour.

In contrast to the Durbanville wines, Paarl Cabernet Sauvignon (warm climate) from the south side were significantly higher in TA, colour and aroma intensities, as well as in mouthfeel, compared to wine from the north side. Alcohol, $\mathrm{pH}$, acid intensity and astringency were not significantly different between the sides. The tasters preferred wines from the south side. Hunter and Volschenk (2018) found that acid intensity was significantly different between the north and south sides of the canopy in Shiraz wines from South Africa. Allegro et al. (2019) reported that increased light exposure of grapes could result in decreased grape acidity.

\section{Pinotage}

Hunter et al. (2010) found that vines planted to N-S directions receive high light exposure in the fruit zone in the morning and afternoon. The west side of the canopies of Darling Pinotage wines (warm climate) showed that the increase in grape bunch light exposure induced an increase in aroma and acid intensity. Alcohol, TA, pH, colour intensity, mouthfeel, astringency and overall quality were not significantly different between sides. Aroma and acid intensity were significantly different between the east and west sides. Hunter and Volschenk (2018) reported that acidity was significantly different between the east and west sides of canopies in Shiraz wines from Robertson, South Africa. Allegro et al. (2019) reported that increased temperature in the fruit zone (N-S vine direction) did not modify mouthfeel or astringency of Grechetto Gentile wines from Spain. Hunter and Volschenk (2018) found that Shiraz wines from the east side of the canopy (N-S direction) were not significantly different in colour intensity from wines from the west side. They also reported that wines from the north side (E-W direction) were not significantly different in colour from wines from the south side.

Durbanville Pinotage wines (cool climate) from the east side were significantly higher in alcohol, $\mathrm{pH}$, TA, colour and aroma intensity compared to wines from the west side. Acid intensity and astringency were significantly highest in wines from the west side. The tasters preferred wines from the east side. The lack of differences in the mouthfeel of wines from canopy sides from both Darling and Durbanville are explained by the findings of Gawel et al. (2013), who reported that mouthfeel differences are more evident at a 


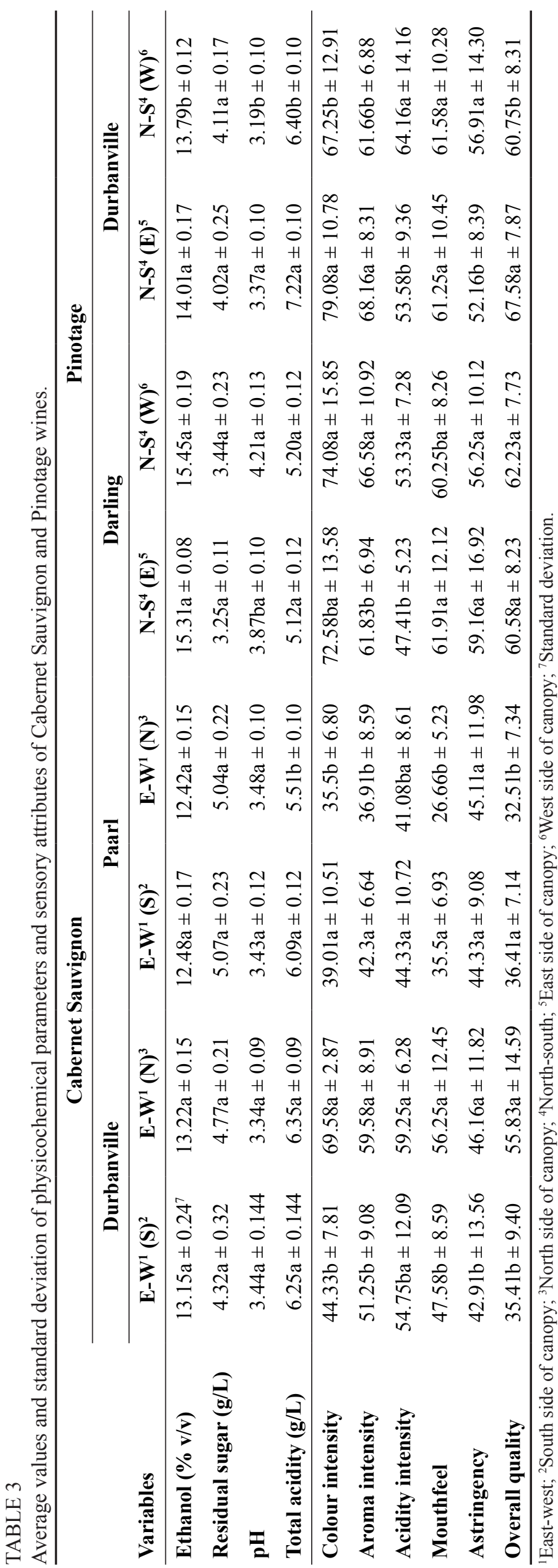


wine alcohol content of $c a .13 \%$.

The high astringency found in Durbanville Cabernet Sauvignon and Pinotage from the north and west sides respectively may be a result of the direct contribution of low pH to this mouthfeel sensation (Gawel et al., 2013). Phenolics can contribute to astringency and mouthfeel (Ferrer-Gallego et al., 2014); however, the mouthfeel of phenolics is complex because tannins and hydroxycinnamic acids have a synergistic effect on the perception of wine structure. Allegro et al. (2019) found that wines from exposed Grechetto Gentile grape bunches were more astringent and bitter than shaded grapes.

Generally, wines with the highest levels of alcohol scored highest in colour intensity and aroma intensity, as well as in overall quality. Casassa et al. (2013) reported that alcohol concentration defines the preferred sensory attributes in Merlot wines. Alcohol levels, $\mathrm{pH}$, polysaccharides, glycerol and TA (Demiglio \& Pickering 2008; Fontoin et al., 2008; McRae \& Kennedy 2011) affect the perception of astringency and mouthfeel. Increasing the wines' viscosity and/or $\mathrm{pH}$ can result in a decrease in the intensity of astringency, but an increase in the concentration of alcohol has no effect on the perception of astringency (Oberholster, 2008).

Sadras et al. (2012) found that TA, pH, aroma intensity and astringency could have additive effects with temperature and canopy side. Sadras et al. (2012) also reported that grape cultivar and canopy side responded with effects that were greater in warmer climates compared to cooler climates. Bonada and Sadras (2014) showed that the effect of diurnal temperature on grape berry composition has practical implications for wine attributes.

\section{CONCLUSIONS}

The results of this investigation confirm that canopy side affects overall wine quality. Differences among wines were distinguishable by means of selected sensory attributes and physicochemical characteristics. This investigation illustrates the variation in sensory attribute scores of Cabernet Sauvignon and Pinotage wines from different canopy sides and regions. From this perspective, canopy side in a vineyard of a specific region, orientated to an $\mathrm{E}-\mathrm{W}$ or N-S direction that favours colour intensity, aroma intensity and/or mouthfeel, could result in improved wine quality. The results are based on samples representing only a single vintage. Light incidence and temperature monitoring throughout berry development were not reported. Therefore, future investigations should focus on samples collected over at least three consecutive vintages, as well as include temperature and photosynthetic active radiation monitoring.

\section{LITERATURE CITED}

Allegro, G., Pastore, C., Valentini, G. \& Filippetti, I., 2019. Effects of sunlight exposure on flavonol content and wine sensory of the white winegrape Grechetto Gentile. Am. J. Enol. Vitic. doi:10.5344/ajev.2019.17108

Bonada, M. \& Sadras, V.O., 2014. Review: Critical appraisal of methods to investigate the effect of temperature on grapevine berry composition. Aust. J. Grape Wine Res. 21, 1-17.

Bureau, S.M., Baumes, R.L. \& Razungles, A.J., 2000. Effect of vine or bunch shading on the glycosylated flavour precursors of Vitis vinifera L. cv. Syrah. J. Agric. Food Chem. 48, 1290-1297.
Casassa, F.L., Beaver, C.W., Mireles, M.S. \& Harbertson, J.F., 2013. Effects of extended maceration and ethanol concentration on the extraction and evolution of phenolics, colour components and sensory attributes of Merlot wines. Aust. J. Grape Wine Res. 19, 25-39.

Chorti, E.S.G., Guidoni, S., Ferrandino, A. \& Novello, V., 2010. Effect of different cluster sunlight-exposure levels on ripening and anthocyanin accumulation in Nebbiolo grapes. Am. J. Enol. Vitic. 61, 23-30.

Cortell, J.M., Halbleib, M., Gallagher, A.V., Righetti, T.L. \& Kennedy, J.A., 2007. Influence of vine vigour on grape (Vitis vinifera L. cv. Pinot noir) anthocyanins. 1. Anthocyanin concentration and composition in fruit. J. Agric. Food Chem. 55, 6575-6584.

Demiglio, P. \& Pickering, G.J., 2008. The influence of ethanol and $\mathrm{pH}$ on the taste and mouthfeel sensations elicited by red wine. Food Agric. Environ. 6, 143-150.

Downey, M.O., Dokoozlian, N.K. \& Krstic, M.P., 2006. Cultural practice and environmental impacts on the flavonoid composition of grapes and wine: A review on recent research. Am. J. Enol. Vitic. 57, 257-268.

Ferrer-Gallego, R., Hernández-Hierro, J.M., Rivas-Gonzalo, J.C. \& Escribana-Bailón, M.T., 2014. Sensory evaluation of bitterness and astringency sub-qualities of wine phenolic compounds: Synergistic effect and modulation by aromas. Food Res. Int. 62, 1100-1107.

Fontoin, H., Saucier, C., Teissedre, P.L., \& Glories, Y., 2008. Effect of pH, ethanol, and acidity on astringency and bitterness of grape-seed tannin oligomers in model wine solution. Food Qual. Pref. 19, 286-291.

Friedel, M., Weber, M., Zacharias, J., Patz, C-D. \& Stoll, M., 2012. Impact of microclimate on berry quality parameters of white Riesling (Vitis vinifera L.). In: Proc. IX ${ }^{\text {th }}$ Int. Terroir Congress, July 2012, Dijon, France. pp. $8-11$.

Gawel, R., 1997. The use of language by trained and untrained wine tasters. J. Sens. Stud. 12, 267-284.

Gawel, R., 1998. Red wine astringency: A review. Aust. J. Grape Wine Res 4, 74-95.

Gawel, R. \& Godden, P.W., 2008. Evaluation of the consistency of wine quality assessments from expert wine tasters. Aust. J. Grape Wine Res. 14, $1-9$

Gawel, R., Van Sluyter, S.C., Smith, P.A. \& Waters, E.J., 2013. Effect of pH and alcohol on perception of phenolic character in white wine. Am. J. Enol. Vitic. 64, 425-429.

Gil, M., Esterueleas, M., González, E., Kontoudakis, N., Jiméz, J., Fort, F., Canals, J.M., Hermosín-Gutiérrez, I. \& Zamora, F., 2013. Effect of two different treatments for reducing grape yield in Vitis vinifera cv. Syrah on wine composition and quality: Berry thinning versus cluster thinning. J. Agric. Food Chem. 61, 4968-4978.

González-Neves, G., Barreiro, L., Gil, G. \& Carbonneau, A., 2004. Anthocyanic composition of Tannat grapes from the south region of Uruguay. Anal. Chim. Acta 513, 197-201.

Gregan, S.M., Wargent, J.J., Liu, L., Shinkle, J., Hofman, R., Winefield, C., Trought, M. \& Jordan, B., 2012. Effects of solar ultra violet radiation and canopy manipulation on the biochemical composition of Sauvignon blanc grapes. Aust. J. Grape Wine Res. 18, 227-238.

Guinard, J.X., Pangborn, R.M. \& Lewis, M.J., 1996. Time course of astringency in wine upon repeated ingestion. Am. J. Enol. Vitic. 37, 184189.

Hunter, J.J. \& Volschenk, C.G., 2008. Implication of grapevine row orientation in South Africa. In: Proc. VIII ${ }^{\text {th }}$ Int. Terroir Congress, July 2008 , Nyon, Switzerland. pp. $336-342$.

Hunter, J.J. \& Volschenk, C.G., 2018. Chemical composition and sensory properties of non-wooded and wooded Shiraz (Vitis vinifera L.) wine as affected by vineyard row orientation and grape ripeness level. J. Sci. Food Agric. 98, 2689-2704 
Hunter, J.J., Volschenk, C.G. \& Bonnardot, V., 2010. Linking grapevine row orientation to a changing climate in South Africa. Proc. Sixtieth German Grape and Wine Congress, Stuttgart, Germany. pp. $60-70$.

Louarn, G., Dauzat, J., Le Coeur, J. \& Le Bon, E., 2008. Influence of trellis system and shoot positioning on light interception and distribution in two grapevine cultivars with different architectures: an original approach based on 3D canopy modelling. Aust. J. Grape Wine Res. 14, 143-152.

Mané, C., Souquet, J.M., Olle, D., Verries, C., Veran, F., Mazerolles, G. \& Fulcrand, H., 2007. Optimisation of simultaneous flavanol, phenolic acid, and anthocyanin extraction from grapes using an experimental design: Application to the characterisation of Champagne grape varieties. J. Agric. Food Chem. 55, 7224-7233.

McRae, J.M. \& Kennedy, J.A., 2011. Wine and grape tannin interactions with salivary proteins and their impact on astringency: A review of current research. Molecules 16, 2348-2350.

Minnaar, P.P., De Villiers, A.J. \& Hunter, J.J., 2013. Anthocyanins, flavanols and flavonols of Vitis vinifera L. cv. Syrah wines as affected by row orientation and ripeness levels. In: Proc. $18^{\text {th }}$ Int. Symp. GiESCO, July 2013, Porto, Portugal. pp. $417-421$.

Oberholster, A., 2008. Investigation of chemical and sensory properties of red wine pigments. $\mathrm{PhD}$ thesis, University of Adelaide, Adelaide, Australia.

Næs, T., Brockhoff, P.B. \& Tomic, O., 2010. Statistics for sensory and consumer science. John Wiley \& Sons, West Sussex, UK.

Noble, A.C., 1995. Application of time-intensity procedures for the evaluation of taste and mouth feel. Am. J. Enol. Vitic. 46, 128-133.

Ott, R.L., 1998. An Introduction to Statistical Methods and Data Analysis. Duxbury Press, Belmont, CA.
Pérez-Lamela, C., García-Falcón, M.S., Simal-Gándara, J. \& OrriolsFernádez, I., 2007. Influence of grape variety, vine system, and oenological treatments on the colour stability of young red wines. Food Chem. 101, 601-606.

Río-Segade, S., Soto-Vázquez, E., Vázquez-Rodríguez, E.I. \& RegoMartínez, J.F., 2009. Influence of training system on chromatic characteristics and phenolic composition in red wines. Eur. Food Res. Technol. 229, 763-770.

Rustioni, L., Rossoni, M., Calatroni, M. \& Failla, O., 2011. Influence of bunch exposure on anthocyanin extractability from grape skins (Vitis vinifera L.). Vitis 50, 137-143.

Ryona, I., Pan, B.S., Intrigliolo, D. S., Lakso, A.N. \& Sacks, G.L., 2008. Effect of cluster light exposure on 3-isobutyl-2-methoxypyrazine synthesis and degradation patterns in red wine grapes (Vitis vinifera L. cv. Cabernet franc). J. Agric. Food Chem. 56, 10838-10846.

Sadras, V.O., Moran, M.A. \& Bonada, M., 2012. Effects of elevated temperature in grapevine. I. Berry sensory traits. Aust. J. Grape Wine Res. 19, 95-106.

SAS Institute Inc., 1999. SAS/STAT User's Guide, Volume 2, Version 9 (1 ${ }^{\text {st }}$ ed). Campus Drive, Cary, North Carolina, 27513.

Shapiro, S.S. \& Wilk, M.B., 1965. An analysis of variance test for normality (complete samples). Biometrika 52, 591-611.

Vilanova, M. \& Martinez, C., 2007. First study of determination of aromatic compounds of red wine from Vitis vinifera cv. Castanal grown in Galicia (NW Spain). Eur. Food Res. Technol. 224, 431-436. 